\title{
ATUALIZACOES
}

\section{ALGUMAS IDÉIAS BÁSICAS DA NEUROPSIQUIATRIA MODERNA}

\author{
Publio Salles Silva *
}

Victor Horsley foi um dos primeiros cirurgióes a remover um foco cortical com o fim de tratar um caso de epilepsia; seguiram-se tentativas cirúrgicas que culminaram com os trabalhos de Förster, figura que ocupa posição de destaque na ciência neurológica contemporânea, pela vultosa contribuição e pelo seu trabalho, seguindo o exemplo de Horsley e Ferrier, quanto à estimulação eléctrica cortical, ao estudo das localizações e à cirurgia das epilepsias. Foi com èste grande mestre que W. Penfield, o fundador da Escola Neurológica de Montreal, iniciou-se na especialidade em que tanto se tem distinguido.

Terminados seus estudos médicos, Penfield trabalhou com Sherrington e no National Institute, Queen Square, em Londres. A seguir, trabalhou com Cajal, mas em direto contacto com Hortega, com quem permaneceu 6 meses e com o qual publicou um trabalho sôbre epilepsias. De regresso aos Estados Unidos, trabalhou no Presbyterian Hospital, em Nova York, sendo, depois, convidado para dirigir um Departamento de Neurocirurgia no Royal Victoria Hospital, em Montreal. Neste Hospital fêz Penfield suas primeiras excisões corticais em 1928. Com o auxílio da Fundação Rockfeller iniciou a construção de um Instituto Neurológico, inaugurado em 1932, tendo $H$. Cushing profetizado que ali teria início um novo capitulo da Neurocirurgia. Não deixa de ser simbólico o fato de que neste mesmo ano Cushing se aposentou do cargo de professor na Universidade de Harvard, abandonando as atividades cirúrgicas.

Penfield orientou-se logo para a neurocirurgia, especialidade altamente desenvolvida graças à contribuição de Cushing e seus discípulos, entre os quais se salientaram Dandy e Olivecrona. Com êste grupo de neurocirurgiōes fôra atingido o máximo de perfeição no que tange à cirurgia dos tumores cerebrais. Cushing já fizera também algumas tentativas de localização no córtex motor, mediante o emprêgo dá estimulação eléctrica.

Com a inauguração do Montreal Neurological Institute foi iniciada nova era de trabalhos. Penfield, adepto das idéias de Hughlings Jackson, prati-

* Da Clinica Psiquiátrica da Fac. Med. da Univ. de São Paulo. 
cou a cirurgia cortical em bases puramente clinicas por muitos anos, até que $H$. Jasper trouxe o concurso da electrencefalografia para a localização dos focos epileptógenos, imprimindo aos trabalhos um cunho neurofisiológico. Vinte e dois anos de experiência e pesquisas foram cristalizados no livro de Jasper e Penfield, "Epilepsia e Anatomia Funcional do Cérebro Humano", publicado em 1954.

Jasper dedicou-se ao estudo dos ritmos eléctricos normais e patológicos do cérebro, aproveitando-se das craniotomias feitas por Penfield, sob anestesia local, para análise electrencefalográfica em superfície e profundidade; Jasper demonstrou que, ao contrário do que a anatomia clássica faz supor, com seus pontos de reparos precisos, a grande plasticidade do cërebro humano ante às vicissitudes que ocorrem em seu desenvolvimento, faz com que não haja dois cérebros absolutamente iguais, havendo amplas variações, muito embora o plano de construção seja o mesmo.

A metódica utilizada por Penfield e Jasper permite levantar um mapa do cérebro que está sendo examinado, com suas áreas da palavra, áreas sensitivas e motoras. Tendo em vista a lesão demonstrada pelo traçado eléctrico, pode o cirurgião decidir entre o sacrifício de alguma função, quando seja o caso, ou a permanência do quadro clínico anterior; algumas vêzes consegue êle planejar a operação de forma a remover o processo patológico com a preservação de tôdas as funções; outras vêzes consegue apenas uma solução de compromisso. Em alguns casos o tratamento cirúrgico é contraindicado pela impossibilidade de poupar funçōes fundamentais, pois de nada valeria ter um paciente curado da epilepsia mas afásico ou totalmente hemiplégico. É impossível planejar uma excisão cortical antes da operação e, durante esta, o electrencefalografista deve orientar a conduta do cirurgião.

Freqüentemente é dito que a cirurgia da epilepsia é contraditória, pois retira uma lesão cerebral para deixar uma cicatriz cirúrgica. Os trabalhos feitos por Penfield e Hortega sôbre cicatrizações cerebrais mostram que a natureza histológica das cicatrizes depende da forma e técnica usadas na excisão cortical. Em particular, o uso abusivo do bisturi eléctrico, deixando cicatrizes que deformam o córtex da vizinhança, gera condições propícias para a anóxia e, conseqüentemente, para novos focos epileptógenos. Não admira, pois, o mau resultado obtido por alguns neurocirurgiões.

Nas operações de excisão cortical feitas conforme a técnica preconizada por Penfield. a vida do paciente não é posta em risco, o confôrto durante o ato cirúrgico é grande e o psicólogo, que investiga e conversa com o paciente durante a operação, testemunha a amigável relação que se estabelece entre os cirurgiões e o paciente. Este sistema de trabalho, que tamanha soma de conhecimentos tem dado à fisiologia cerebral, requer, porém, grande sacrifício e fôrça de vontade por parte dos cirurgiôes, dos electrencefalografistas e de seus assistentes, pois tais operações às vêzes se prolongam por 6 a 8 horas. 
Os trabalhos da Escola de Montreal sôbre as localizações cerebrais, sôbre as disritmias sincronas bilaterais secundárias a focos corticais e que devem ser distinguidas das primitivas, sôbre os focos tempolais, sôbre a área motora suplementar e a segunda área sensitiva, sôbre a anatomia do pequeno mal, são alguns exemplos da brilhante orientação dada por Penfield. Não cabe nos limites dêste trabalho, a análise de tôdas essas contribuições. Relembraremos apenas duas idéias de Penfield, hauridas de suas experiências neurocirürgicas.

A primeira diz respeito ao mecanismo da memória. Foi possível reproduzir vivências passadas com tôda a nitidez, mediante estimulação eléctrica do lobo temporal; Penfield concluiu que nessa região, ou na sua vizinhança, se localiza a memória, gravada como se fôra um disco e capaz de ser reprcduzida mediante estímulos apropriados; as descrições que Jackson fizera da síndrome do "dejá-vu" em casos de lesões temporais, seriam a contrapartida clinica destas observações cirúrgico-experimentais. Penfield chegou a dizer que sua afirmativa teria para as ciências biológicas o mesmo significado que teve a descoberta da excitabilidade do córtex motor, feita poi Fritsch e Hitzig em 1870. Entretanto, observaçōes ulteriores demonstraram o que já se sabia de há muito, isto é, que o problema da memória não pode ser formulado ou explicado por esta forma simplista.

A segunda idéia é mais colorida e mais rica de conseqüências.

É sabido que em um dos tipos clínicos de ataque epiléptico não há auras que previnam o paciente, iniciando-se a crise com súbita perda de consciência. Partindo do pressuposto de que as crises convulsivas se iniciam em uma lesão sediada em área cuja função dá a tonalidade ao tipo de aura (focos no córtex occipital ocasionando aura de tipo visual, focos no córtex motor determinando auras de tipo motor, etc.) é evidente que as que se iniciam com súbita perda da consciência deverão ter origem na sede da consciência, cuja localização é discutida. Hughlings Jackson o colocara, como o mais alto nivel da função nervosa, nos lobos frontais. Dandy chegara à conclusão de que a sede da consciência deveria estar no lobo frontal esquerdo ou dominante; entretanto, J. Poppen ligou a artéria cerebral anterior do hemisfério dominante em numerosos casos, sem ocasionar distúrbios da consciência.

Lhermite, com a descrição das alucinoses pedunculares originadas no tronco cerebral e Le Gros Clark com seus estudos sôbre a estrutura e funções dos núcleos talâmicos, deram a Penfield bases para o conceito da fisiologia do sistema centrencefálico, que seria o centro integrador de tôda a atividade cortical; as crises epilépticas que se originam neste sistema, "crises do mais alto nivel do sistema nervoso", se iniciariam com perda da consciência. Na prática o problema é mais complexo, pois focos de vizinhança podem ativar êste sistema centrencefálico, ocasionando crises de tipo idêntico. 
Apareceram, a partir de então, numerosos trabalhos de Neurofisiologia visando dar realidade funcional a êste sistema. Morrison e Dempsey verificaram que a estimulação de certos núcleos talâmicos situados na linha média era capaz de ativar de forma síncrona tôda a atividade eléctrica cortical, havendo, pois, verdadeiro "pace-maker" regulador de vastas áreas corticais. Jasper aproveitou-se desta idéia e concluiu que ai estaria a sede do pequeno mal epiléptico, que se manifesta, no electrencefalograma, por uma disritmia bilateral sincrona de pontas-ondas a 3 por segundo; assim, descreveu a anatomia do pequeno mal e reproduziu-o experimentalmente em gatos, pela estimulação eléctrica do centro mediano e de outros núcleos do sistema intralaminar. Por outro lado, Magoun e colaboradores descreveram o sistema ativador reticular ascendente que, iniciando-se no bulbo e protuberância, se estenderia até o mesencéfalo. Éste sistema seria o responsável pela contínua ativação do córtex no estado de vigília; sua destruição experimental em animais ou por processos patológicos no homem determina o sono ou coma, como também ocorre nas preparaçōes de encéfalo-isolado de Bremer. Todo o sistema aferente sensitivo e sensorial envia colaterais para esta formação reticular do tronco cerebral que tem atividades facilitadoras e inibidoras em relação às funções infra-segmentares medulares. Jasper descreveu numerosas conexões do córtex cerebral com êste sistema reticular do tronco cerebral.

A integrar-se neste conjurto vieram os trabalhos de Granit, de Estocolmo, demonstrando que a sensibilidade postural é regulada pelas fibras musculares intrafusais que, por sua contração, diminuem o comprimento do fuso, sensibilizando-o ao estiramento muscular; a inervação dêstes pequenos músculos intrafusais, dispostos em paralelo com as fibras musculares comuns, é feita por células das pontas anteriores da medula (neurônios gama) sujeitas ao contrôle supra-segmentar chamado gama-aferente, cuja origem parece estar na formação reticular do tronco cerebral. Um músculo, mesmo em repouso, isto é, quando a eletromiografia comum revcla completo silêncio eléctrico, possui inervação ativa e funcionante que se destina ao músculo intra-fusal. Assim, os distúrbios do tono muscular, especialmente a espasticidade e a rigidez, devem ser reanalisados em função destas transcendentes descobertas de Granit e colaboradores.

A formação reticular do tronco cerebral, recebendo mensagens de todo o sistema sensitivo-sensorial, ativa o córtex no mecanismo da atenção. $O$ córtex, por sua vez, ativa a formação reticular responsável pelo mecanismo postural, que constitui o "background" para as contrações reflexas e voluntárias. A um estímulo periférico, corresponde uma primeira resposta cortical da área específica, que é mediada pelo núcleo talâmico correspondente, que atua como "relais" em uma rêde de transmissão; esta primeira resposta cortical não se acompanha da percepção consciente e é mediada pelo sistema lemniscal, sem participação da formação reticular. Mas êste mesmo sistema lemniscal que provocou no córtex a primeira resposta, excita também a for- 
maçăo reticular que, então, ativa o córtex pelo sistema talâmico difuso, provocando uma segunda resposta cortical que se acompanha da percepção consciente do primeiro estímulo. A porção rostral dêste sistema talâmico atua como uma lente, fazendo convergir para determinadas áreas do córtex os estímulos do sistema talâmico difuso, trazendo, assim, para a luz da consciência, a parte escolhida de tôdas as percepções ou excitações internoceptivas e externoceptivas, e fracionando, pelo mecanismo da atenção, a multitude de estímulos que lutam para alcançar a consciência.

No passado, aliás de poucos anos, era dada importância ao caráter geral da "arousal response" ou reação de alerta. Agora estuda-se o valor desta reação para localizar as reações corticais e, assim, permitir que apenas fração da realidade interior e exterior atinja a consciência. Parece que um distúrbio básico que se encontra em certas neuroses e psicoses é a baixa dêste limiar, permitindo que grande número de informações ganhe a consciência, tornando difícil ou impossivel a integração đa conduta em moldes lógicos e pragmáticos. A causa primeira das neuroses e psicoses seria a multitude de memórias e dos mais diferentes estimulos atingindo, simultânea e desordenadamente, a consciência.

O sistema centrencefálico está bem. formulado, do ponto de vista clinico e neurofisiológico. Faltam maiores comprovaçōes anatômicas, o que não se deve admirar, considerando a relativa pobreza dos métodos histológicos em uso e suas limitaçōes para demonstrar cadêias de neurônios. W. Nauta desenvolveu uma modificação do método de Bielchowsky de impregnação argêntica e com êle tem feito os mais belos trabalhos da histologia do sistema nervoso em nossos dias, continuando a tradição de Cajal.

No congresso sôbre a formação reticular realizado em Detroit, Gastaut apres€ntou J. Jefferson como o grão-mestre da "religião" reticular. Neste mesmo congresso, Scheibel, ao terminar sua brilhante apresentação sôbre a histologia do tronco cerebral, estudada com o método de Golgi, disse que se eliminarmos o que há de secundário, o sistema reticular é o sistema nervoso. Na mesma ocasião Bishop falou sôbre a semelhança existente entre a camada plexiforme do córtex e a formação reticular.

No passado, culminando com os trabalhos de Pavlov, foi dada primazia ao córtex cerebral para explicar os fenômenos da consciência. Nos primeiros anos de vida do "sistema centrencefálico" esta função foi transferida para o diencéfalo. Entretanto, torna-se cada vez mais evidente que não se pode dissociar o córtex do diencéfalo, que devem ser considerados como unidade funcional. É verdade que se pode remover vastas áreas corticais sem provocar distúrbios de consciência - de outra forma não haveria cirurgia cerebral - ao passo que pequenas lesões nas áreas diencéfalo-mesencefálicas mergulham o paciente no coma. Estas áreas são críticas para o fenômeno da consciência que requer, no entanto, também a ação do córtex. A Neurologia tem estudado os aspectos quantitativos da consciência, ou seja, as 
variaçōes da reação de alerta até o estado de coma. O problema está não só na formulação quantitativa dêstes distúrbios ou de suas variações fisiológicas, mas também nas alteraçōes qualitativas. Já estão sendo ensaiadas formulaçōes fisiológicas para êstes processos.

Com mais experiência e conhecimentos, a distância que hoje separa a Neurologia da Psiquiatria se tornará cada vez menor, até sua completa fusão em uma só disciplina. Considerando a herança dualistica e metafísica da Psiquiatria, é extraordinário o grau de independência que ela já atingiu como ciência positiva. Interpretações de fatos clínicos são agora possiveis à luz das novas doutrinas neurofisiológicas. Tomemos, para exemplo, a síndrome de Balint, ou paralisia psíquica do olhar, nas lesões parietais bilaterais que eliminam grande parte do sistema talâmico difuso, impedindo que o campo visual periférico chegue à luz da consciência. $O$ mesmo acontece na sindrome de Gerstmann, caracterizada pela disgrafia, acalculia, confusão do lado direito com o esquerdo e agnosia para os dedos. Também se aplica isso à interpretação da anosognosia, tudo mostrando que a chamada patologia parietal deverá ser reexaminada sob novas bases anátomo-patológicas. As recentes aquisições da Neurofisiologia permitem, ainda, interpretar as diferenças entre amorfossínteses e agnosias, sendo que nas primeiras a quantidade de informações que chega ao córtex está limitada por lesões do sistema talâmico específico; nas agnosias as fibras lesadas situam-se nos sistemas talâmico difuso e nas correlaçōes córtico-talámicas do hemisfério dominante. A segunda resposta cortical, proveniente do hemisfério são, obscurece a resposta do hemisfério lesado, explicando, assim, o fenômeno da extinção de um dos estimulos simétricos nas lesōes parietais.

Pode-se dizer, portanto, que grande parte da patologia clássica precisa ser revista e reformulada. Existem casos de tumores parietais sediados no hemisfério dominante que só determinam sintomas sensitivos e motores; em outros casos ocorre afasia sensorial; em outros o quadro parietal é riquíssimo, inclusive ccm impercepção do hemiespaço e distúrbios do esquema corporal. Quais as causas destas diferenças de comportamento diante de lesões aparentemente idênticas quanto à situação? Mesmo considerando a plasticidada das localizações cerebrais, deve haver outro fator mais importante. O que aconteceu ao cérebro como um todo? Qual o grau e intensidade das degenerações walerianas c retrógradas em todo êste emaranhado de fibras? No estudo destas lesões até agora tem sido analisados, pràticamente, apenas os sistemas de fibras mielínicas; entretanto, as fibras amielínicas constituem cêrca de $50 \%$ das fibras de conexão corticais e córtico-talâmicas. A lesão demonstrada é como se fôsse a môsca prêsa a uma complexa teia ou novêlo tridimensional; o que aconteceu à distância neste delicado e complicado sistema?

A tradição de Cajal precisa ser reencontrada e métodos mais delicados e precisos devem ser descobertos. Ante a complexidade que a neurofisiolo- 
gia nos mostra, a relativa pobreza dos métodos anatômicos deve servir de estímulo à imaginação dos patologistas na procura de novos recursos.

Walshe criticou a obra da Escola de Montreal, em nome do chamado ponto de vista operacional em biologia, dizendo, que quando se estimula o sistema nervoso, interfere-se com a função normal e a resposta é um sintoma, no sentido de von Monakov, de função desintegrada; o estímulo eléctrico não é, pois, a forma fisiológica pela qual o movimento se processa normalmente. Fulton respondeu-lhe que os problemas de fisiologia nervosa serão resolvidos pela experimentação e não pela reflexão filosófica, o que provocou a sarcástica réplica de Walshe: "Tenho muita desconfiança dos que procuram contrapor experiência à reflexão".

Há, ainda, o problema dos parâmetros da excitabilidade e a variabilidade dos mapas corticais de acôrdo com as características do estímulo eléctrico usado. Mas, se correlacionarmos os dados positivos obtidos durante estas estimulações corticais com os negativos provenientes das excisões experimentais ou dados da patologia, poderemos definir um conceito dinâmico das localizações cerebrais. O estado de excitação central define, a cada momento, o grau de excitabilidade e a natureza das respostas de qualquer área cortical, que pode ser inteiramente inexcitável durante os períodos de depressão, descritos e estudados por A. Leão.

A contribuição de $K$. Klèist foi notável no que diz respeito à doutrina das localizações. Infelizmente, a maior parte dos casos que line serviram de base - traumatizados de guerra - teve um estudo patológico muito pobre. quando se considera a complexidade anatômica do cérebro humano.

Uma linha de trabalho que tem revelado dados surpreendentes é a que usa microelectrodos, pesquisando a atividade eléctrica de camadas corticais ou de células isoladas. Jasper disse que êste método é o eqüivalente fisiológico do método de Golgi. Tem sido possivel demonstrar que, muitas vezes, quando os electrodos de superfície nada revelam, apenas a um milimetro abaixo, verdadeira tempestade eléctrica se processa. Estudando o pulsar isolado do neurônio poder-se-ia um dia compreender como é possivel que da atividade harmoniosa de bilhões destas unidades, possa surgir um tipo de função - o pensamento - que ouse e anseie por explicar-se a si mesmo.

Diremos, agora, rápidas palavras sôbre a psicocirurgia.

O nome em si é absurdo, pois a cirurgia se processa no cérebro. Após o trabalho pioneiro de Egas Muniz, muitos centros americanos se entregaram a verdadeira hecatombe de lobos frontais. Métodos foram criados para torná-la acessivel a tôdas as bôlsas e sem as despesas do internamento hospitalar. Conhecido autor publica estatísticas considerando o número da população possivvelmente tributária desta cirurgia, especificando os minutos que leva cada operação e a economia do método; para o autor haveria tempo e dinheiro suficientes para que todos a pudessem usar. Esta forma de abordar 
problema de tamanha gravidade foge inteiramente ao espírito do genial português, que se cercara dos maiores cuidados ao formular as indicaçōes do método.

Nos últimos 5 anos, o desenvolvimento da psicofarmacologia, o aparecimento das drogas frenotrópicas, neurolépticas ou psicoterapêuticas, com todo um novo dicionário de neologismos, trouxe, como conseqüência, o declínio da lobotomia frontal; quase todos os relatórios sôbre o uso destas drogas em esquizofrênicos crônicos mostram sua superioridade sôbre a psicocirurgia.

Torna-se, porém, cada vez mais evidente, no dizer de Ayd, que a falta de ação benéfica dêstes neurolépticos em muitos casos de depressão crônica, de reações obsessivo-compulsivas ou em casos fronteiriços, como na esquizofrenia pseudo-neurótica, deixa apreciável número de pacientes para o domínio da lobotomia, única que pode ajudá-los. Todos nós desejamos que os progressos da quimioterapia tornem possivel a cura dos distúrbios mentais relegando para o passado as intervenções cruentas. Até que êste dia chegue é de lamentar que o recurso cirúrgico seja necessário, restando como consôlo a oportunidade que ela dá para estudar funções do sistema nervoso. No Instituto Neurológico de Nova York, apesar do grande consumo de ataráxicos no edifício vizinho, o Instituto Psiquiátrico, são recebidos semanalmente, 2 a 3 casos para leucotomia pré-frontal. A mesma média de pacientes é atendida na Lahey Clinic, enviados pelo Boston Psychopatic Hospital. O mesmo acontece com as indicações de Slater no Queen Square Hospital, em Londres.

A experiência de L. Pool, durante os trabalhos do Grey Stone Project, levou-o à conclusão de que só se obtém efeito psicocirúrgico nas intervençōes sôbre o lobo frontal e, neste, não importa a localização, sendo o fator quantitativo o único importante. Assim, o cirurgião tem ao scu lado uma balança para pesar a quantidade de lobo frontal excisado $-20,30$ ou 40 gramas - de acôrdo com a gravidade do caso. A incidência de epilepsia no pós-operatório imediato ou tardio chegou, em certas séries, a $20 \%$, principalmente quando foi empregada a topectomia.

A experiência de Le Beau com a cirurgia frontal seletiva dá valor à localização da excisão quanto aos efeitos cirúrgicos (cingulectomias, topectomias de convexidade, secção de face interna, ressecção orbitária, etc.). Le Beau descreve um típico episódio de hemorragia subaracnóidea, com sangue no líquor e nenhum característico de mal comicial, como sendo ataque epiléptico. Este autor faz cingulectomias em casos de focos temporais típicos; não nos sentimos seguros do critério que êle usou na seleção dos casos e análise dos resultados.

Quando conhecermos mais sôbre localizações funcionais, a cirurgia seletiva poderá ter melhor base. É inseguro falar de cirurgia seletiva tomando como reparo pontos cranianos ou ventriculares e falar de excisão de áreas quando a citoarquitetônica mostra que uma série de áreas são difíceis de 
serem identificadas ao microscópio, sendo, portanto, não identificáveis a ôlho nu. Além disso, o valor funcional da maioria destas áreas é questionável quando as consideramos isoladamente.

Um dos mais belos aspectos da chamada psicocirurgia está na prática das hemisferectomias, indicadas inicialmente para os casos de distúrbios de conduta associados à paralisia cerebral e, às vêzes, a crises epilépticas incontroláveis. Tivemos oportunidade de participar de dez hemisferectomias feitas no Instituto Neurológico de Nova York e acompanhar as transformações apresentadas pelos pacientes após as operações. Houve casos de verdadeiras curas quanto ao quadro mental, com desaparecimento das crises convulsivas e melhora da espasticidade dos membros paréticos. É evidente, pois, que o hemisfério cerebral, lesado antes da idade de um ano, passara ao outro os encargos que lhe competiam, mas ficara reduzido à condição de um grande foco de córtex "nociferous", no dizer de Penfield. Melhor seria chamar a esta operação de hemidecorticação, pois nela são respeitados os gânglios da base.

À psicocirurgia está reservado, ainda, lugar no tratamento das dôres causadas pelos tumores incuráveis. Há casos em que as cordotomias ou tractotomias não abolem a dor ou não são indicadas, restando o consôlo de se dar ao paciente um fim de vida mais humano. A hipofisectomia é de grande valor no tratamento dos carcinomas com metástases ósseas e pulmonares.

A cirurgia estereotática, com o progresso dos estudos sôbre os sistemas de coordenadas das diferentes regiões subcorticais, já está possibilitando intervençōes, mesmo em casos de tumores profundos. Para o futuro ela terá, por certo, grande desenvolvimento, pois será mais fácil lesar um pequeno núcleo talâmico do que excisar extensas áreas corticais ou seccionar todo um sistema de fibras. Para êsse tipo de cirurgia são usadas correntes eléctricas e substâncias químicas ou radiodtivas para produzirem lesões estereotàticamente orientadas. Para o futuro, possivelmente, feixes convergentes de ultrassons provocarão estas mesmas lesões, com maior precisão; esta última técnica já está em uso em vários laboratórios norte-americanos.

No que diz respeito à localização de lesões intracranianas, W. H. Sweet desenvolveu o método chamado da coincidência, com o uso do arsênico radioativo, que fornece excelente "sombra" das lesões, sendo o único método de futuro entre todos os apresentados até agora com isótopos radioativos.

Para terminar, imaginemos como o fêz Sherrington, uma arquitetura de linhas e pontos nodais reunidos, em uma das extremidades, a um grande emaranhado de nós, o cérebro, e que, num diminuendo de complexidade, se termina por um tronco, a medula espinhal; representemos a atividade dêste sistema por pequenos pontos luminosos; algumas luzes estacionárias cintilam rìtmicamente, rápida ou vagarosamente; outros pontos de luz caminham 
em linhas seriadas, com diferentes velocidades. As luzes cintilantes ocupam os pontos nodais; êstes nós são, ao mesmo tempo, pontos de convergência, de junção e de divergência nas trajetórias das centelhas móveis.

Observemos êste sistema durante o sono, quando apenas em alguns pontos esparsos e distantes há focos luminosos com débeis pulsações; o grande emaranhado de nós repousa em quase completa escuridão; de tempos em tempos, em alguns lugares, cintilam ou se deslocam pontos de luz, que em breve se extinguem. Se continuamos a observar o sistema, verificaremos que, sùbitamente, impressionante transformação se opera, em um crescendo; na grande extremidade que estivera quase em trevas, miriades de luzeiros resplandescem. E o grande emaranhado se transforma em espaço coruscante de rítmicas faiscações, com centelhas deslocando-se em tôdas as direções. É como se a via láctea se entregasse a um cósmico bailado. Ràpidamente a grande cabeça se transforma em um tear encantado, onde milhões de faiscantes lançadeiras tecem um modêlo que perpètuamente se dissolve, um modêlo sempre cheio de significado, mas efêmero. Desperta-se o cérebro e, com êle, regressa a consciência.

Esta é a nossa pálida tradução das palavras de Sherrigton.

Compreender e, às vêzes, reparar êste delicado e cambiante sistema é a missão da neuropsiquiatria.

Clinica Psiquiátrica, Hospital das Clinicas da Fac. Med. da Univ. de Säo PauloSão Paulo, Brasil. 